\title{
Comparison of Efficacy of Different Surgical Techniques for Benign Prostatic Obstruction
}

\author{
Jiwoong Yu' ${ }^{1}$, Byong Chang Jeong ${ }^{1}$, Seong Soo Jeon ${ }^{1}$, Sung Won Lee ${ }^{1}$, Kyu-Sung Lee ${ }^{1,2}$ \\ ${ }^{1}$ Department of Urology, Samsung Medical Center, Sungkyunkwan University School of Medicine, Seoul, Korea \\ ${ }^{2}$ Department of Medical Device Management and Research, SAIHST, Sungkyunkwan University, Seoul, Korea
}

Purpose: We compared success rates of 3 surgical techniques (holmium laser enucleation of the prostate [HoLEP], transurethral resection of the prostate [TURP], and photoselective laser vaporization prostatectomy [PVP]) for treatment of benign prostatic obstruction (BPO). We aimed to identify preoperative clinical variables and urodynamic parameters that predict surgical success.

Methods: A total of 483 patients who underwent surgical treatment for BPO at Samsung Medical Center between 2006 and 2017 were retrospectively analyzed; of these 361,81 , and 41 patients underwent HoLEP, TURP, and PVP, respectively. Prostate-specific antigen, prostate volume, urodynamic parameters, and International Prostate Symptom Score (IPSS)/quality of life (QoL) index were evaluated preoperatively; uroflowmetry, postvoid residual urine, and IPSS/QoL index were measured 6 months postoperatively. Surgical success was defined based on IPSS, maximum flow rate, and QoL index and predictive factors were identified using multiple logistic regression analyses.

Results: Success rates of HoLEP, TURP, and PVP were 67.6\%, 65.4\%, and 34.1\%, respectively, and the HoLEP and TURP groups were not significantly different. Regression analysis revealed prostate volume $\geq 50 \mathrm{~mL}$ and bladder outlet obstruction index (BOOI) $\geq 40$ to be independent factors predicting HoLEP success. Only high preoperative QoL could predict the success of TURP, whereas other urodynamic parameters remained unrelated.

Conclusions: Patients treated with HoLEP and TURP displayed equivalent efficacies, but PVP was relatively less efficient than both. Preoperative variables of prostate volume $\geq 50 \mathrm{~mL}$ and BOOI $\geq 40$ were independent predictive factors for the success of HoLEP but not of TURP.

Keywords: Benign prostatic obstruction; Benign prostatic hyperplasia; Holmium laser enucleation of prostate; Transurethral resection of prostate; Laser vaporization prostatectomy; Urinary bladder neck obstruction

- Research Ethics: This study was approved by the Institutional Review Board (IRB) of Samsung Medical Center (approval number: SMC 202005-003-001). Informed consent was waived by the IRB.

- Conflict of Interest: No potential conflict of interest relevant to this article was reported.

\section{INTRODUCTION}

Benign prostatic hyperplasia (BPH) is a histological diagnosis referring to the proliferation of smooth muscle and epithelial cells within the prostatic transition zone. In aging males, the histological prevalence of BPH increases at 40 years of age, reaching $60 \%$ at 60 years and $80 \%$ at 80 years [1]. In some cases, $\mathrm{BPH}$ leads to benign prostatic enlargement, which may eventually cause a benign prostatic obstruction (BPO). Lower urinary tract symptoms (LUTS) related to BPO are also common in ag-

Corresponding author: Kyu-Sung Lee (iD https://orcid.org/0000-0003-0891-2488 Department of Urology, Samsung Medical Center, Sungkyunkwan University School of Medicine, 81 Irwon-ro, Gangnam-gu, Seoul 06351, Korea Email: ksleedr@skku.edu

Submitted: August 25, 2020 / Accepted after revision: September 19, 2020 
ing males, with approximately three-quarters of the male population suffering from this condition by the age of 70 years [2]. Furthermore, LUTS have a significant impact on the quality of life (QoL) in terms of interruptions to daily living, work productivity, and even psychological well-being [3,4].

Transurethral resection of the prostate (TURP), a practice established in the 1930s, is traditionally accepted as the gold standard of surgical treatment for BPO. The advent of the laser in the 1990s has led to this historical standard being repeatedly challenged by a variety of new surgical methods [5]. Until the 2000s, TURP was still used an effective treatment, but its use has now decreased and the use of lasers for BPO treatment has significantly increased [6].

Usage of a laser for BPO treatment involves tissue coagulation or vaporization for debulking of prostatic tissue. Photoselective laser vaporization prostatectomy (PVP) uses a high power laser to instantly evaporate tissue and create a large cavity, as in TURP [7]. Another technique, holmium laser enucleation of the prostate (HoLEP), uses a holmium laser to enucleate the prostatic adenoma from the surgical capsule in a manner similar to that of open prostatectomy.

Here, we investigated the efficacies of TURP, HoLEP, and PVP based on estimated criteria, specifically Homma criteria, for treatment efficacy [8]. We evaluated the efficacy of treatment based on patient characteristics such as prostate volume and urodynamic parameters. Finally, we evaluated preoperative factors predictive of successful TURP and HoLEP.

\section{MATERIALS AND METHODS}

\section{Patient Population and Assessment}

This study was approved by the Institutional Review Board (IRB) of Samsung Medical Center (approval number: SMC 2020-05-003-001). Informed consent was waived by the IRB.

Between January 2006 and December 2017, 773 patients underwent TURP, HoLEP, or PVP for the treatment of BPO at our institution. Patients with preoperative urodynamic study (UDS) data were included and those with insufficient data, postoperative diagnosis of prostate cancer, or previous surgical treatment for BPO were excluded. Finally, we analyzed 483 patients with more than 6 months of follow-up data.

All patients underwent initial clinical evaluations such as recording of medical history and physical examination, including digital rectal examination, and were scored using the International Prostate Symptom Score (IPSS). Demographic data in- cluded age, prostate volume, and serum prostate-specific antigen (PSA) level. Body mass index (BMI) was available only for patients who underwent TURP or HoLEP. Patients were preoperatively assessed using transrectal ultrasound and UDS. UDS was performed as per International Continence Society recommendations [9]. Urodynamic parameters including maximal cystometric capacity, maximum flow rate (Qmax), and detrusor pressure at Qmax (PdetQmax) were recorded. Calculations of bladder outlet obstruction index (BOOI; BOOI $=$ PdetQmax2Qmax) and bladder contractility index (BCI; BCI = PdetQmax+ 5Qmax) were performed [10]. BOOI $\geq 40$ was defined as bladder outlet obstruction, and BCI $<100$ was defined as weak bladder contractility. Detrusor overactivity (DO) is a urodynamic variable characterized by involuntary detrusor contractions during the bladder filling phase.

The operation duration was recorded for all patients, along with resected tissue weight and resection portion (resected weight/preoperative prostate volume [\%]) for patients who underwent TURP or HoLEP. Six months after surgery, all patients were assessed using IPSS and uroflowmetry with postvoid residual urine (PVR). The complications associated with the operations were assessed, and medications for storage symptoms (anticholinergics or beta-adrenergic agonists) were also recorded.

\section{Operative Technique}

TURP was performed as per standard techniques using a $26 \mathrm{~F}$ continuous flow resectoscope (Storz, Tuttlingen, Germany). Resection was performed using a standard tungsten wire loop with a mono-polar cutting current of $120 \mathrm{~W}$ and coagulating current of $80 \mathrm{~W}$. HoLEP was performed as described by Gilling, with some modifications [11]. After dividing the prostate into anatomical lobes, enucleation of each lobe was performed in a retrograde fashion using a high-powered holmium laser (80$100 \mathrm{~W}$ ), delivered by a SlimLine 550-mm fiber (Lumenis, Inc., Yokneam, Israel) through the 26F continuous flow resectoscope system. For tissue morcellation and retrieval, we used a $26 \mathrm{~F}$ nephroscope with a VersaCut Tissue Morcellator (Lumenis, Inc.). PVP was performed using an 80-W potassium-titanylphosphate laser delivered by a GreenLight system (GreenLight PV; Laserscope, San Jose, CA, USA). The laser was delivered through a $600-\mu \mathrm{m}$ side-deflecting fiber. A standard $23 \mathrm{~F}$ continuous flow resectoscope with a laser bridge was used for this procedure and sterile $0.9 \%$ saline solution for irrigation.

TURP and HoLEP were performed on hospitalized patients and PVP was performed in the day-surgery center. In the TURP 
and HoLEP groups, the urethral catheter was removed on the day urine became sufficiently clear and in the PVP group, on the first postoperative day.

\section{Estimating Efficacy of Surgery}

The definition of treatment success was based on criteria developed by Homma et al. [8], who presented 4 domains constituting efficacy of BPO treatment: symptoms, function, anatomy, and QoL. The domains were evaluated based on 4 variables: IPSS, Qmax, prostate volume, and QoL index. Overall efficacy was defined as median efficacy grades of the symptoms, function, and QoL domains. Efficacy grades (excellent, good, fair, and poor) for each domain have been summarized in Table 1. Treatment was considered successful if overall efficacy demonstrated excellent or good grade.

\section{Statistical Analysis}

Descriptive statistics were presented as mean \pm standard deviation. Student $\mathrm{t}$-test or 1-way analysis of variance was used for continuous variables, and chi-square test for categorical variables. Multivariable logistic regression analyses were performed using preoperative urodynamic parameters and other relevant clinical variables to identify predictive factors for the success of

Table 1. Criteria for determining the efficacy of individual domains and proportion of patients for each efficacy grade

\begin{tabular}{lc}
\hline Domain & Value \\
\hline Symptom (Post/Pre ratio of IPSS) & $\leq 0.25$ \\
Excellent & $\leq 0.50$ \\
Good & $\leq 0.75$ \\
Fair & $>0.75$ \\
Poor & \\
QoL (Pre-Post ratio of QoL index) & $\geq 4$ \\
Excellent & 3 \\
Good & 2,1 \\
Fair & $\leq 0$ \\
Poor & \\
Function (Post-Pre ratio of Qmax) & $\geq 10$ \\
Excellent & $\geq 5$ \\
Good & $\geq 2.5$ \\
Fair & $<2.5$ \\
Poor &
\end{tabular}

Pre, preoperative; Post, postoperative; IPSS, International Prostate Symptom Score; QoL, quality of life; Qmax, maximum flow rate.
TURP or HoLEP. Prostate volume with maximum Youden index was used as a cutoff for predicting surgical success. These analyses were conducted using the IBM SPSS Statistics ver. 21.0 (IBM Co., Armonk, NY, USA). Statistical calculations, scatterplot displays with least-squares regression line, and 95\% confidence intervals for the slope were performed using Rex (Version 3.3.0, RexSoft Inc., Seoul, Korea), a user interface for R (https://www.r-project.org/). All P-values were 2-tailed, and P< 0.05 was considered statistically significant.

\section{RESULTS}

We analyzed 361, 81, and 41 patients who underwent HoLEP, TURP, and PVP, respectively. Table 2 lists the preoperative baseline characteristics. Patients treated with HoLEP had larger prostate volumes than those treated with TURP or PVP (HoLEP vs. TURP, $\mathrm{P}=0.004$; HoLEP vs. PVP, $\mathrm{P}<0.001)$. However, the IPSS and QoL index were comparable across all 3 groups. The proportion of patients with bladder outlet obstruction was significantly smaller in the PVP group, with only $34.1 \%$ (14 patients) having BOOI $\geq 40$. The proportion of patients with bladder outlet obstruction in the HoLEP and TURP groups was 62.3\% (225 patients) and 72.8\% (59 patients), respectively, with no statistically significant differences between the 2 groups $(\mathrm{P}=$ 0.074).

In terms of perioperative and postoperative parameters, the mean operation duration was significantly shorter in the PVP group than in the HoLEP and TURP groups $(\mathrm{P}<0.001)$ (Table 3 ), with no significant difference between the HoLEP and TURP groups ( 63 minutes vs. 62 minutes, $\mathrm{P}=0.784$ ). Both resected tissue weight and resection portion were higher in the HoLEP group than in the TURP group. PVP was significantly poorer for most outcomes (IPSS, QoL index, and Qmax, but not PVR). Between the HoLEP and TURP groups, Qmax was significantly higher in the HoLEP group $(19.8 \mathrm{~mL} / \mathrm{sec}$ vs. 14.8 $\mathrm{mL} / \mathrm{sec}, \mathrm{P}<0.001$ ) whereas other outcomes were comparable.

Table 4 shows the operation outcomes for each domain based on the estimation criteria and Fig. 1 shows preoperative and postoperative changes in the 3 estimation domains. Patients treated with PVP showed significantly lower improvement in the symptom and function domains than those treated with HoLEP or TURP $(\mathrm{P}=0.001, \mathrm{P}<0.001$, respectively). The HoLEP group showed significantly more improvement in the function domain than the TURP group $(\mathrm{P}<0.001)$. Overall, the success rates of the operations were $67.6 \%, 65.4 \%$, and $34.1 \%$ in 
Table 2. Preoperative baseline characteristics

\begin{tabular}{|c|c|c|c|c|c|c|}
\hline \multirow{2}{*}{ Characteristic } & \multirow{2}{*}{$\operatorname{HoLEP}(\mathrm{n}=361)$} & \multirow{2}{*}{$\operatorname{TURP}(\mathrm{n}=81)$} & \multirow{2}{*}{$\operatorname{PVP}(n=41)$} & \multicolumn{3}{|c|}{$\mathrm{P}$-value } \\
\hline & & & & HoLEP vs. TURP & TURP vs. PVP & HoLEP vs. PVP \\
\hline \multicolumn{7}{|l|}{ Demographic data } \\
\hline Age (yr) & $69.2 \pm 7.4$ & $65.6 \pm 6.4$ & $67.0 \pm 6.4$ & $<0.001$ & 0.243 & 0.074 \\
\hline $\operatorname{BMI}\left(\mathrm{kg} / \mathrm{m}^{2}\right)(\mathrm{n}=442)$ & $24.5 \pm 2.8$ & $24.8 \pm 2.7$ & - & 0.405 & - & \\
\hline PSA (ng/mL) & $4.1 \pm 5.0$ & $3.4 \pm 3.8$ & $1.7 \pm 1.6$ & 0.222 & 0.001 & $<0.001$ \\
\hline Prostate volume $(\mathrm{mL})$ & $63.4 \pm 32.9$ & $52.4 \pm 23.2$ & $32.0 \pm 13.0$ & 0.004 & $<0.001$ & $<0.001$ \\
\hline$\geq 50$ & $200(55.4)$ & $40(49.4)$ & $4(9.8)$ & 0.326 & $<0.001$ & $<0.001$ \\
\hline IPSS total & $22.3 \pm 7.0$ & $22.1 \pm 8.2$ & $22.2 \pm 7.6$ & 0.821 & 0.950 & 0.929 \\
\hline IPSS $\geq 20$ & $242(67.0)$ & $51(63.0)$ & $26(63.4)$ & 0.483 & 0.961 & 0.641 \\
\hline Storage & $8.8 \pm 3.3$ & $9.1 \pm 3.6$ & $9.3 \pm 3.9$ & 0.453 & 0.799 & 0.444 \\
\hline Voiding & $13.5 \pm 4.8$ & $13.0 \pm 5.2$ & $12.9 \pm 4.8$ & 0.395 & 0.930 & 0.452 \\
\hline QoL index & $4.3 \pm 1.0$ & $4.4 \pm 1.3$ & $4.5 \pm 1.2$ & 0.487 & 0.678 & 0.219 \\
\hline \multicolumn{7}{|l|}{ Urodynamic parameters } \\
\hline $\operatorname{MCC}(\mathrm{mL})$ & $370.2 \pm 103.5$ & $371.7 \pm 90.5$ & $386.8 \pm 97.9$ & 0.904 & 0.401 & 0.329 \\
\hline $\mathrm{Qmax}(\mathrm{mL} / \mathrm{sec})$ & $8.0 \pm 3.8$ & $9.0 \pm 3.6$ & $9.7 \pm 3.5$ & 0.026 & 0.317 & 0.006 \\
\hline $\operatorname{PVR}(\mathrm{mL})$ & $118.3 \pm 124.6$ & $100.4 \pm 100.6$ & $82.5 \pm 69.7$ & 0.229 & 0.312 & 0.006 \\
\hline BOOI & $54.8 \pm 31.6$ & $55.8 \pm 26.0$ & $37.9 \pm 17.6$ & 0.784 & $<0.001$ & $<0.001$ \\
\hline BOOI $\geq 40$ & $225(62.3)$ & $59(72.8)$ & $14(34.1)$ & 0.074 & $<0.001$ & $<0.001$ \\
\hline $\mathrm{BCI}$ & $106.4 \pm 35.6$ & $113.9 \pm 28.3$ & $93.9 \pm 27.0$ & 0.042 & $<0.001$ & 0.009 \\
\hline BCI $<100$ & $170(47.1)$ & $28(34.6)$ & 27 (65.9) & 0.041 & 0.001 & 0.023 \\
\hline DO & $190(52.6)$ & $45(55.6)$ & $8(43.9)$ & 0.634 & 0.224 & 0.289 \\
\hline
\end{tabular}

Values are presented as mean \pm standard deviation or number (\%).

HoLEP, holmium laser enucleation of the prostate; TURP, transurethral resection of the prostate; PVP, photoselective laser vaporization prostatectomy; BMI, body mass index; PSA, prostate-specific antigen; IPSS, International Prostate Symptom Score; QoL, quality of life; MCC, maximal cystometric capacity; Qmax, maximum flow rate; PVR, postvoid residual urine; BOOI, bladder outlet obstruction index; BCI, bladder contractility index; DO, detrusor overactivity.

Table 3. Perioperative and postoperative parameters

\begin{tabular}{|c|c|c|c|c|c|c|}
\hline \multirow{2}{*}{ Parameter } & \multirow{2}{*}{$\operatorname{HoLEP}(\mathrm{n}=361)$} & \multirow{2}{*}{$\operatorname{TURP}(\mathrm{n}=81)$} & \multirow{2}{*}{$\operatorname{PVP}(n=41)$} & \multicolumn{3}{|c|}{ P-value } \\
\hline & & & & HoLEP vs. TURP & TURP vs. PVP & HoLEP vs. PVP \\
\hline Operation duration (min) & $62.9 \pm 34.3$ & $61.7 \pm 37.6$ & $38.8 \pm 16.6$ & 0.784 & $<0.001$ & $<0.001$ \\
\hline Resection weight (g) & $24.1 \pm 21.1$ & $15.6 \pm 12.3$ & - & $<0.001$ & & \\
\hline Resection portion (\%) & $34.2 \pm 16.7$ & $28.1 \pm 14.8$ & - & 0.003 & & \\
\hline IPSS & $8.5 \pm 7.3$ & $8.1 \pm 6.6$ & $13.5 \pm 8.3$ & 0.663 & $<0.001$ & $<0.001$ \\
\hline Storage & $4.6 \pm 3.1$ & $4.6 \pm 3.0$ & $6.4 \pm 3.4$ & 0.922 & 0.004 & $<0.001$ \\
\hline Voiding & $3.9 \pm 4.9$ & $3.5 \pm 4.4$ & $7.1 \pm 5.4$ & 0.476 & $<0.001$ & $<0.001$ \\
\hline QoL index & $1.9 \pm 1.5$ & $1.8 \pm 1.4$ & $2.8 \pm 1.5$ & 0.532 & $<0.001$ & 0.001 \\
\hline $\mathrm{Qmax}(\mathrm{mL} / \mathrm{sec})$ & $19.8 \pm 10.2$ & $14.8 \pm 7.5$ & $12.0 \pm 7.8$ & $<0.001$ & 0.050 & $<0.001$ \\
\hline PVR (mL) & $32.7 \pm 43.8$ & $38.8 \pm 48.7$ & $48.2 \pm 66.9$ & 0.263 & 0.292 & 0.154 \\
\hline
\end{tabular}

Values are presented as mean \pm standard deviation.

HoLEP, holmium laser enucleation of the prostate; TURP, transurethral resection of the prostate; PVP, photoselective laser vaporization prostatectomy; IPSS, International Prostate Symptom Score; QoL, quality of life; Qmax, maximum flow rate; PVR, postvoid residual urine. 
Table 4. The outcomes of operations for each estimation domain at 6 months after the operations

\begin{tabular}{|c|c|c|c|c|c|c|}
\hline \multirow{2}{*}{ Domain } & \multirow{2}{*}{$\operatorname{HoLEP}(\mathrm{n}=361)$} & \multirow{2}{*}{$\operatorname{TURP}(\mathrm{n}=81)$} & \multirow{2}{*}{$\operatorname{PVP}(\mathrm{n}=41)$} & \multicolumn{3}{|c|}{$\mathrm{P}$-value } \\
\hline & & & & HoLEP vs. TURP & TURP vs. PVP & HoLEP vs. PVP \\
\hline Symptom & & & & 0.926 & 0.001 & $<0.001$ \\
\hline Excellent & $162(44.9)$ & $36(44.4)$ & $4(9.8)$ & & & \\
\hline Good & $104(28.8)$ & $25(30.9)$ & $17(41.5)$ & & & \\
\hline Fair & $41(11.4)$ & $10(12.3)$ & $6(14.6)$ & & & \\
\hline Poor & $54(15.1)$ & $10(12.3)$ & $14(34.1)$ & & & \\
\hline QoL index & & & & 0.671 & 0.051 & 0.081 \\
\hline Excellent & $103(28.5)$ & $28(34.6)$ & $9(22.0)$ & & & \\
\hline Good & $74(20.5)$ & $17(21.0)$ & $5(12.2)$ & & & \\
\hline Fair & $137(38.0)$ & $28(34.6)$ & $16(39.0)$ & & & \\
\hline Poor & $47(13.0)$ & $8(9.9)$ & $11(26.8)$ & & & \\
\hline Function & & & & $<0.001$ & 0.146 & $<0.001$ \\
\hline Excellent & $191(52.9)$ & $24(29.6)$ & $5(12.2)$ & & & \\
\hline Good & $66(18.3)$ & $13(16.0)$ & $6(14.6)$ & & & \\
\hline Fair & $36(10.0)$ & $11(13.6)$ & $6(14.6)$ & & & \\
\hline Poor & $68(18.8)$ & $33(40.7)$ & $24(58.5)$ & & & \\
\hline Success & $244(67.6)$ & $53(65.4)$ & $14(34.1)$ & 0.709 & 0.001 & $<0.001$ \\
\hline
\end{tabular}

Values are presented as number (\%).

HoLEP, holmium laser enucleation of the prostate; TURP, transurethral resection of the prostate; PVP, photoselective laser vaporization prostatectomy; QoL, quality of life.
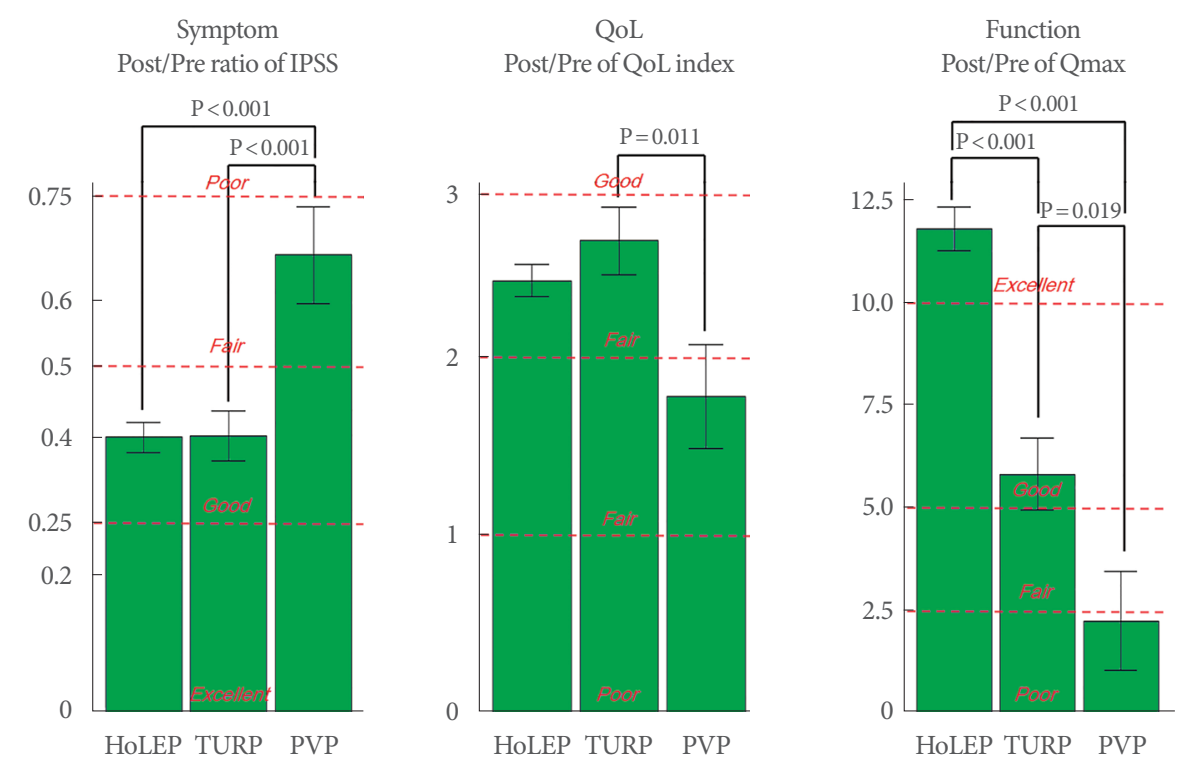

Fig. 1. Comparing calculated values of surgical outcome for each domain. IPSS, International Prostate Symptom Score; QoL, quality of life; Qmax, maximum flow rate; HoLEP, holmium laser enucleation of the prostate; TURP, transurethral resection of the prostate; PVP, photoselective laser vaporization prostatectomy. Only statistically significant comparisons are marked with P-values. 
HoLEP, TURP, and PVP groups, respectively. The success rate was comparable between the HoLEP and TURP groups $(\mathrm{P}=$ 0.709), but the PVP group was significantly lower than both groups $(\mathrm{P}<0.001)$.

In the HoLEP group, patients who underwent successful surgery were younger $(\mathrm{P}=0.003)$, had lower $\mathrm{BMI}(\mathrm{P}=0.019)$, higher preoperative PSA levels $(\mathrm{P}=0.001)$, and greater prostate volumes $(\mathrm{P}=0.002)$ (Table 5). Among the preoperative urodynamic parameters, $\mathrm{Qmax}(\mathrm{P}=0.001), \mathrm{BOOI}$, and $\mathrm{BCI}(\mathrm{P}<0.001)$ were higher in patients with successful outcomes. In the TURP group, preoperative IPSS $(\mathrm{P}=0.021)$ and $\mathrm{QoL}$ index $(\mathrm{P}=0.004)$ were higher in patients who underwent successful surgeries (Table 5). However, there was no difference in other urodynamic parameters.

Upon performing multivariable logistic regression analyses to identify predictive factors for the successful operations (Table 6), prostate volume $\geq 50 \mathrm{~mL}$ and $\mathrm{BOOI} \geq 40$ were found to be independent predictive factors for success of HoLEP (odds ratio, 2.958 and 2.088; 95\% confidence interval, 1.710-5.116 and 1.239-3.518; $\mathrm{P}<0.001$ and $\mathrm{P}=0.006$, respectively). However, only high preoperative QoL index was associated with success of TURP (odds ratio, 1.628; 95\% confidence interval, 1.039$2.550 ; \mathrm{P}=0.033$ ).

Fig. 2 shows that the trend lines of prostate volume and BOOI in the HoLEP group to be distinctly different depending on success rates, but it is not so for the TURP group. Fig. 3A shows the success rates of HoLEP and TURP for different ranges of prostate volume. Although the success rates of HoLEP and TURP were comparable for patients with prostate volumes less than 50 $\mathrm{cc}(\mathrm{P}=0.152)$, the success rate of HoLEP was significantly higher for patients with prostate volumes ranging from $50 \mathrm{~mL}$ to 100 $\mathrm{mL}$ than for the TURP (79.7\% vs. $63.2 \%, \mathrm{P}=0.030)$. Fig. $3 \mathrm{~B}$ shows the success rates of HoLEP and TURP depending on the presence or absence of bladder outlet obstruction according to

Table 5. Comparison of preoperative variables based on the surgical success of HoLEP

\begin{tabular}{|c|c|c|c|c|c|c|}
\hline \multirow{2}{*}{ Variable } & \multicolumn{3}{|c|}{ HoLEP } & \multicolumn{3}{|c|}{ TURP } \\
\hline & Unsuccessful $(\mathrm{n}=117)$ & Successful $(n=244)$ & $\mathrm{P}$-value & Unsuccessful $(\mathrm{n}=28)$ & Successful $(n=53)$ & P-value \\
\hline \multicolumn{7}{|l|}{ Demographic data } \\
\hline Age (yr) & $70.8 \pm 7.6$ & $68.4 \pm 7.2$ & 0.003 & $64.1 \pm 6.4$ & $66.3 \pm 6.2$ & 0.143 \\
\hline $\mathrm{BMI}\left(\mathrm{kg} / \mathrm{m}^{2}\right)$ & $25.0 \pm 2.9$ & $24.3 \pm 2.8$ & 0.019 & $25.5 \pm 2.6$ & $24.5 \pm 2.7$ & 0.093 \\
\hline PSA (ng/dL) & $2.9 \pm 4.2$ & $4.7 \pm 5.3$ & 0.001 & $2.4 \pm 1.6$ & $3.9 \pm 4.5$ & 0.035 \\
\hline Prostate volume (mL) & $55.6 \pm 35.7$ & $67.2 \pm 30.8$ & 0.002 & $50.8 \pm 20.7$ & $53.2 \pm 24.5$ & 0.660 \\
\hline$\geq 50$ & $42(35.9)$ & $158(64.8)$ & $<0.001$ & $14(50.0)$ & $26(49.1)$ & 0.936 \\
\hline IPSS total & $22.4 \pm 7.1$ & $22.3 \pm 7.0$ & 0.848 & $19.3 \pm 9.2$ & $23.6 \pm 7.2$ & 0.021 \\
\hline IPSS $\geq 20$ & $80(68.4)$ & $162(66.4)$ & 0.708 & $15(53.6)$ & $36(67.9)$ & 0.203 \\
\hline Storage & $9.3 \pm 3.2$ & $8.6 \pm 3.3$ & 0.091 & $8.0 \pm 4.1$ & $9.8 \pm 3.2$ & 0.033 \\
\hline Voiding & $13.2 \pm 4.9$ & $13.6 \pm 4.7$ & 0.383 & $11.3 \pm 5.7$ & $13.9 \pm 4.7$ & 0.033 \\
\hline QoL index & $4.3 \pm 1.1$ & $4.4 \pm 1.0$ & 0.476 & $3.9 \pm 1.5$ & $4.7 \pm 1.2$ & 0.004 \\
\hline \multicolumn{7}{|l|}{ Urodynamic parameters } \\
\hline $\operatorname{MCC}(\mathrm{mL})$ & $363.9 \pm 89.0$ & $373.2 \pm 109.8$ & 0.425 & $369.0 \pm 77.7$ & $373.2 \pm 97.4$ & 0.845 \\
\hline $\mathrm{Qmax}(\mathrm{mL} / \mathrm{sec})$ & $9.0 \pm 4.0$ & $7.5 \pm 3.7$ & 0.001 & $9.8 \pm 3.5$ & $8.6 \pm 3.6$ & 0.186 \\
\hline $\operatorname{PVR}(\mathrm{mL})$ & $103.2 \pm 107.3$ & $125.6 \pm 131.7$ & 0.111 & $91.8 \pm 112.3$ & $105.0 \pm 94.6$ & 0.579 \\
\hline BOOI & $42.4 \pm 21.9$ & $60.8 \pm 33.8$ & $<0.001$ & $49.9 \pm 24.7$ & $59.0 \pm 26.4$ & 0.135 \\
\hline BOOI $\geq 40$ & $52(44.4)$ & $173(70.9)$ & $<0.001$ & $18(64.3)$ & $41(77.4)$ & 0.208 \\
\hline BCI & $95.1 \pm 33.1$ & $111.9 \pm 35.5$ & $<0.001$ & $108.5 \pm 27.4$ & $116.8 \pm 28.6$ & 0.214 \\
\hline BCI $<100$ & $68(58.1)$ & $102(41.8)$ & 0.004 & $13(46.4)$ & $15(28.3)$ & 0.103 \\
\hline $\mathrm{DO}$ & $57(48.7)$ & $133(54.5)$ & 0.302 & $13(46.4)$ & $32(60.4)$ & 0.230 \\
\hline
\end{tabular}

HoLEP, holmium laser enucleation of the prostate; TURP, transurethral resection of the prostate; BMI, body mass index; PSA, prostate-specific antigen; IPSS, International Prostate Symptom Score; QoL, quality of life; MCC, maximal cystometric capacity; Qmax, maximum flow rate; PVR, postvoid residual urine; BOOI, bladder outlet obstruction index; BCI, bladder contractility index; DO, detrusor overactivity. 
Table 6. Multivariate logistic regression analysis of factors influencing success of the operation

\begin{tabular}{|c|c|c|c|c|}
\hline \multirow{2}{*}{ Variable } & \multicolumn{2}{|c|}{ HoLEP } & \multicolumn{2}{|c|}{ TURP } \\
\hline & OR $(95 \% \mathrm{CI})$ & $\mathrm{P}$-value & OR $(95 \% \mathrm{CI})$ & $\mathrm{P}$-value \\
\hline Age & $0.952(0.919-0.986)$ & 0.006 & $1.067(0.972-1.171)$ & 0.173 \\
\hline BMI & $0.917(0.838-1.004)$ & 0.060 & $0.912(0.741-1.124)$ & 0.912 \\
\hline PSA & $1.016(0.951-1.084)$ & 0.644 & $1.136(0.892-1.447)$ & 0.301 \\
\hline IPSS $\geq 20$ & $0.753(0.415-1.366)$ & 0.35 & $1.430(0.412-4.957)$ & 0.573 \\
\hline QoL index & $1.111(0.849-1.455)$ & 0.441 & $1.628(1.039-2.550)$ & 0.033 \\
\hline \multicolumn{5}{|c|}{ Prostate volume } \\
\hline$<50$ & Reference & & Reference & \\
\hline$\geq 50$ & $2.958(1.710-5.116)$ & $<0.001$ & $0.416(0.121-1.429)$ & 0.164 \\
\hline BOOI $\geq 40$ & $2.088(1.239-3.518)$ & 0.006 & $0.590(0.158-2.200)$ & 0.432 \\
\hline $\mathrm{BCI}<100$ & $0.817(0.478-1.397)$ & 0.460 & $0.344(0.096-1.240)$ & 0.103 \\
\hline DO & $0.974(0.574-1.650)$ & 0.921 & $1.070(0.332-3.452)$ & 0.910 \\
\hline
\end{tabular}

HoLEP, holmium laser enucleation of the prostate; TURP, transurethral resection of the prostate; OR, odds ratio; CI, confidence interval; BMI, body mass index; PSA, prostate-specific antigen; IPSS, International Prostate Symptom Score; QoL, quality of life; BOOI, bladder outlet obstruction index; BCI, bladder contractility index; DO, detrusor overactivity.
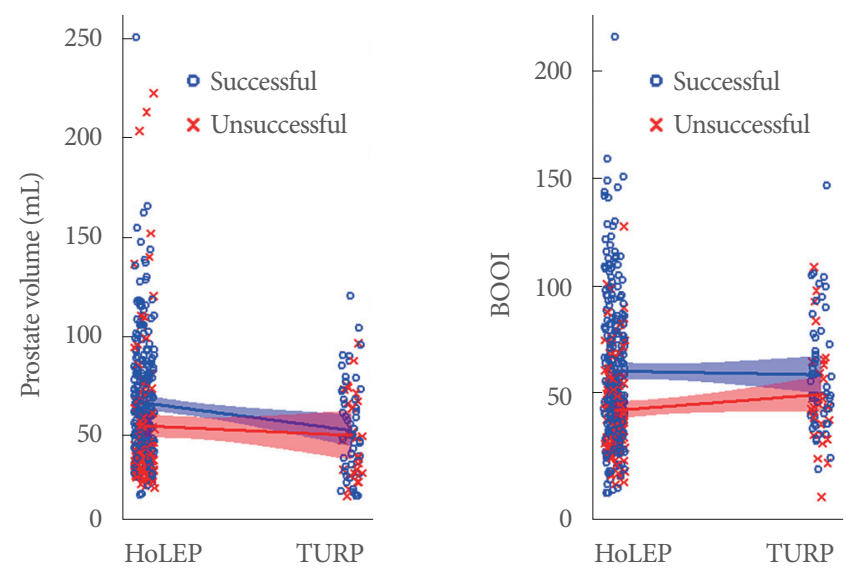

Fig. 2. Scatterplot of prostate volume and BOOI as per the operations. Blue circles represent patients with successful outcomes. Red crosses represent patients with unsuccessful outcomes. Blue and red curves represent the least-squares regression lines with 95\% confidence intervals for the slope in the patients with successful outcomes and unsuccessful outcomes, respectively. HoLEP, holmium laser enucleation of the prostate; TURP, transurethral resection of the prostate; BOOI, bladder outlet obstruction index.

BOOI. There was no difference between the success rate of HoLEP and TURP with or without bladder outlet obstruction $(\mathrm{P}=$ 0.838 and $\mathrm{P}=0.241$, respectively).

In terms of postoperative complications, bladder neck contracture or urethral stricture occurred in $0.8 \%$ (3 patients) of the HoLEP group, 2.5\% (2 patients) of the TURP group. Stress urinary incontinence after operation occurred only in the HoLEP group, with 15 patients (4.2\%) reporting urine leakage at 6 months after the operation. No complications were reported in the PVP group. Among all patients, a total of 59 patients (12.2\%) took anticholinergics or beta-adrenergic agonists at 6 months after the operations. Of 235 patients who preoperatively reported DO, 39 patients $(16.6 \%)$ took anticholinergics or beta-adrenergic agonists. In contrast, of 207 patients without DO, significantly fewer patients 17 (8.2\%) took medications for his storage symptoms $(\mathrm{P}=0.008)$.

\section{DISCUSSION}

Among the elderly, $\mathrm{BPO}$ represents the most prevalent nonmalignant genitourinary condition facing contemporary urologists. TURP has long been considered the standard treatment option for BPO patients who require surgical intervention. Many other alternatives have been investigated after the introduction of lasers in the field, allowing the development of minimally invasive techniques and reducing the risks of the TURP such as bleeding and transurethral resection syndrome $[5,12$, 13].

We compared the success rates of 3 surgical techniques (TURP, HoLEP, and PVP) and investigated potential preoperative clinical factors and urodynamic parameters affecting surgical suc- 

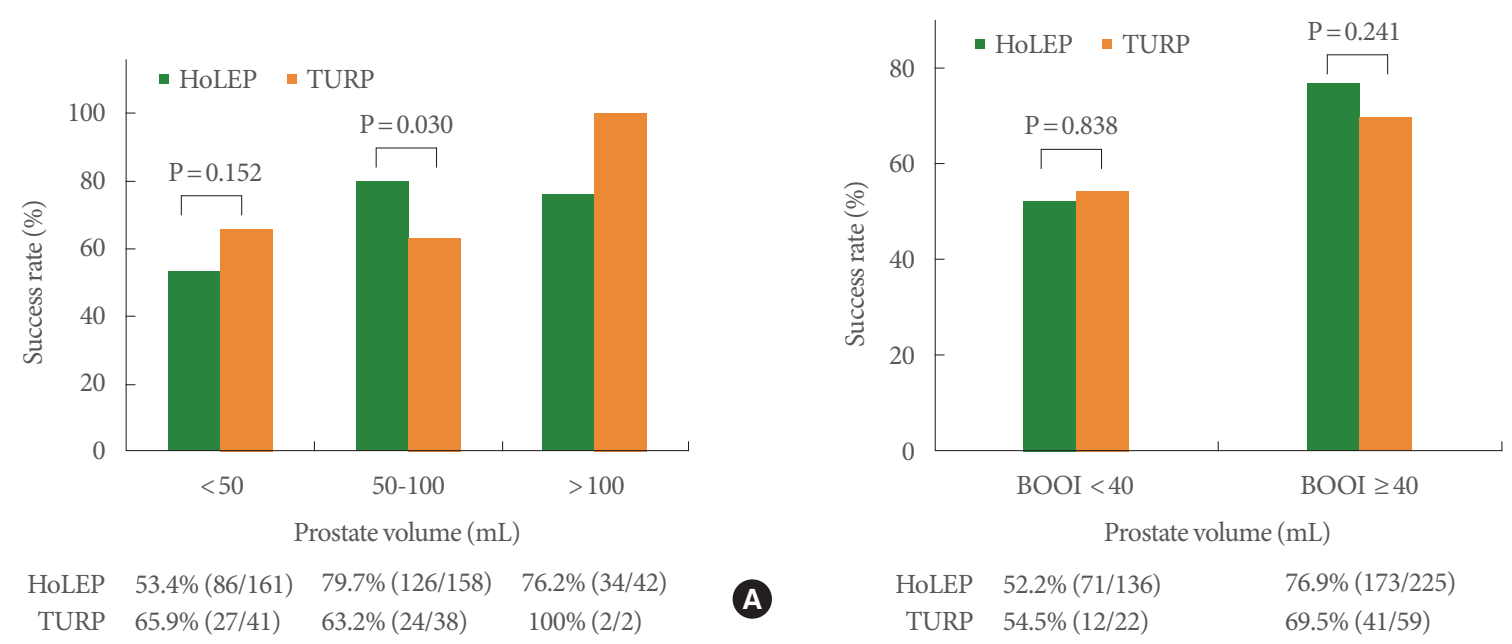

Fig. 3. (A) The success rate of HoLEP and TURP for different ranges of prostate volume. (B) The success rates of HoLEP and TURP depending on the presence or absence of bladder outlet obstruction according to BOOI. HoLEP, holmium laser enucleation of the prostate; TURP, transurethral resection of the prostate; BOOI, bladder outlet obstruction index.

cess. To the best of our knowledge, this is the first study comparing 3 surgical techniques simultaneously performed in one institution, and predicting their respective success rates using urodynamic parameters.

It was necessary to evaluate surgical success, or lack thereof, using subjective symptoms (IPSS/QoL) and objective indicators (uroflowmetry). We utilized criteria outlined by Homma et al. [8], who established 4 domains for efficacy evaluation: symptom, function, anatomy, and QoL. They defined overall efficacy as the median grade of the symptoms, function, and QoL domains. They reported that the dichotomous evaluation of success using these criteria and the agreement rate with judgments of physicians with over 15 years of clinical experience in BPO treatments was approximately $80 \%$.

Based on the criteria, the surgery success rate was significantly lower in the PVP group than in the HoLEP and TURP groups, with no significant differences between the HoLEP and TURP groups. Specifically, we confirmed that among the estimated domains the functional improvement of Qmax was greater in the HoLEP group compared to TURP group. When identifying factors predictive of surgical success in the HoLEP group, prostate volume $\geq 50 \mathrm{~mL}$ and $\mathrm{BOOI} \geq 40$ were found to be independent predictors. However, in the TURP group, only a high baseline QoL, and no other urodynamic parameters, could predict surgical success. Furthermore, the success rate of HoLEP was significantly higher for patients with prostate volumes ranging from $50 \mathrm{~mL}$ to $100 \mathrm{~mL}$ than for the TURP.

There were significant differences in the age and prostate vol- umes of patients among the 3 surgical techniques. However, IPSS and QoL index did not differ among the 3 groups. We proceed with the assumption that age and prostate volume are used as the basis of judgment rather than subjective symptoms when clinicians determining the type of surgery. Tae et al. [14] described the successful treatment of patients with prostates larger than $100 \mathrm{~mL}$ using HoLEP, which was reported to provide a satisfactory outcome in patients with prostate gland larger than $175 \mathrm{~mL}$ with low morbidity [15].

Comparative studies, including randomized controlled trials, comparing TURP to HoLEP or PVP have been summarized in Table 7 [16-20]. According to these studies, PVP is considered to be similar to or worse than TURP in terms of efficacy. A 5-year prospective study has reported PVP to have a higher risk of reoperation due to recurrent adenoma [21]. Also, as per these studies, HoLEP is equivalent to or more efficient than TURP. Notably, previous studies have reported that the operation duration is significantly longer for HoLEP than for TURP. However, in our study, the operation duration was not significantly different between the 2 surgical techniques. It may be because we analyzed more recent procedures, that is, since the introduction of HoLEP in our institution, the surgeons at our hospital have earned much experience in the procedure and gained the technical abilities to shorten the operation duration. Especially HoLEP is known to have a steep learning curve, even with the prospective training structure of a multicenter study, it has been reported that half of the centers did not overcome this learning curve and abandoned HoLEP as a technique [22]. In 
Table 7. Manuscripts that address the surgical outcomes at 6 months after the operations

\begin{tabular}{|c|c|c|c|c|c|}
\hline Study & IPSS & QoL index & $\begin{array}{l}\text { Qmax } \\
(\mathrm{mL} / \mathrm{sec})\end{array}$ & $\begin{array}{l}\text { Resection weight } \\
\text { (g) }\end{array}$ & $\begin{array}{l}\text { Operation duration } \\
\text { (min) }\end{array}$ \\
\hline \multicolumn{6}{|l|}{ HoLEP vs. TURP } \\
\hline Kuntz et al. [16] $(n=200)$ & $\begin{array}{l}2.2 \text { vs. } 3.7 \\
P=0.006\end{array}$ & - & $\begin{array}{l}25.1 \text { vs. } 25.1 \\
P=0.72\end{array}$ & $\begin{array}{l}33 \text { vs. } 37 \\
P=0.17\end{array}$ & $\begin{array}{c}94.6 \text { vs. } 73.8 \\
\mathrm{P}<0.0001\end{array}$ \\
\hline Tan et al. [17] $(\mathrm{n}=61)$ & 6.0 vs. 4.8 & 1.6 vs. 1.5 & 26.4 vs. 20.8 & $\begin{array}{c}40.4 \text { vs. } 24.7 \\
\mathrm{P}<0.05\end{array}$ & - \\
\hline Montorsi et al. [18] $(n=100)$ & $\begin{array}{c}3.9 \text { vs. } 2.9 \\
P=0.72\end{array}$ & $\begin{array}{c}1.0 \text { vs. } 0.6 \\
P=0.25\end{array}$ & $\begin{array}{c}23.1 \text { vs. } 26.5 \\
P=0.007\end{array}$ & $\begin{array}{c}36.1 \text { vs. } 25.4 \\
\mathrm{P}<0.05\end{array}$ & $\begin{array}{l}74 \text { vs. } 57 \\
P<0.05\end{array}$ \\
\hline Current study & $\begin{array}{l}8.5 \text { vs. } 8.1 \\
P=0.663\end{array}$ & $\begin{array}{l}1.9 \text { vs. } 1.8 \\
P=0.532\end{array}$ & $\begin{array}{c}19.8 \text { vs. } 14.8 \\
\mathrm{P}<0.001\end{array}$ & $\begin{array}{c}24.1 \text { vs. 15.6 } \\
\mathrm{P}<0.001\end{array}$ & $\begin{array}{c}62.9 \text { vs. } 61.7 \\
P=0.784\end{array}$ \\
\hline \multicolumn{6}{|l|}{ TURP vs. PVP } \\
\hline Bouchier-Hayes et al. [19] $(n=120)$ & $\begin{array}{c}11.7 \text { vs. } 11.2 \\
\mathrm{P}>0.05\end{array}$ & $\begin{array}{l}2.2 \text { vs. } 2.0 \\
P>0.05\end{array}$ & $\begin{array}{c}17.3 \text { vs. } 20.4 \\
\mathrm{P}<0.05\end{array}$ & - & - \\
\hline Han et al. [20] $(n=67)$ & $\begin{array}{c}6.8 \text { vs. } 10.8 \\
P=0.228\end{array}$ & $\begin{array}{l}2.1 \text { vs. } 2.2 \\
P=0.859\end{array}$ & $\begin{array}{c}15.3 \text { vs. } 16.0 \\
P=0.473\end{array}$ & - & - \\
\hline Current study & $\begin{array}{c}8.5 \text { vs. } 13.5 \\
P<0.001\end{array}$ & $\begin{array}{l}1.9 \text { vs. } 2.8 \\
P=0.001\end{array}$ & $\begin{array}{c}19.8 \text { vs. } 12.0 \\
\mathrm{P}<0.001\end{array}$ & - & $\begin{array}{c}\text { 62.9 vs. } 38.8 \\
\mathrm{P}<0.001\end{array}$ \\
\hline
\end{tabular}

IPSS, International Prostate Symptom Score; QoL, quality of life; Qmax, maximum flow rate; HoLEP, holmium laser enucleation of the prostate; TURP, transurethral resection of the prostate; PVP, photoselective laser vaporization prostatectomy.

particular, difficulty in enucleation of the adenoma was difficult for beginners, and delays at this step have been reported to prolong the operation duration [23].

Previous reports have investigated predictors of surgical success for BPO, but the results have not been consistent. Our institution has reported that the improvement of IPSS after TURP in patients with preoperative weak bladder contractility $(\mathrm{BCI}<$ $100)$ is significantly low [24]. Some studies have suggested that the degree of preoperative bladder outlet obstruction does not significantly affect the efficacy of TURP [25]. On the contrary, others have reported that the efficacy of TURP improves as the preoperative degree of bladder outlet obstruction worsens [26,27]. Seki et al. [28] analyzed 384 BPO patients 1 year after TURP and reported that a severe preoperative bladder outlet obstruction positively predicted postoperative improvement in IPSS and QoL. In our study, preoperative variables of prostate volume $\geq 50 \mathrm{~mL}$ and BOOI $\geq 40$ are independent predictive factors for the success of HoLEP. In contrast, only a high preoperative QoL index, and no other urodynamic parameter, could predict the success of TURP. Further analyses of predictive factors revealed that the trend lines of prostate volume and BOOI distinctly differed depending on success in the HoLEP group. In the TURP group, however, they showed no differences for each of the variables.
There was no difference in the success rate of each operation as per the baseline DO, but there was a statistically significant difference in whether or not a medication for storage symptoms (anticholinergics or beta-adrenergic agonists) was taken 6 months after the operation. As is well known, an overactive bladder may be the result of DO, which develops secondary to BPO. Although several reports revealed the storage symptoms improved significantly in both groups, a significant number of patients with DO reported taking anticholinergics after HoLEP $[29,30]$.

This study has several limitations because it was performed with a retrospective design, possibly leading to selection bias. In addition, the possibility of residual confounding variables cannot be ruled out. The preoperative prostate volume was higher in the HoLEP group than in the TURP and PVP groups. Also, the proportion of patients with $\mathrm{BOOI} \geq 40$ was higher in the HoLEP group than in the PVP group. However, the proportions of patients with prostate volume $\geq 50 \mathrm{~mL}$ and BOOI $\geq 40$ were comparable between the HoLEP and TURP groups. Additionally, the number of patients in the TURP and PVP groups was much smaller than that in the HoLEP group. We included patients with preoperative UDS and more than 6 months of follow-up data. Although the number of patients in the TURP and PVP groups was small, the data regarding the procedures are 
valuable references for evaluating operation outcomes.

In conclusion, this study demonstrated that HoLEP is as efficient as TURP and that PVP is relatively less efficient than both TURP and HoLEP. Preoperative variables of prostate volume $\geq 50 \mathrm{~mL}$ and BOOI $\geq 40$ are independent predictive factors for the success of HoLEP, but not of TURP. HoLEP may be more successful than TURP in patients with a prostate volume of 50 to $100 \mathrm{~mL}$.

\section{AUTHOR CONTRIBUTION STATEMENT}

\author{
- Conceptualization: JY, BCJ, SSJ, SWL, KSL \\ - Data curation: $J Y$ \\ - Formal analysis: JY \\ - Methodology: KSL \\ - Project administration: KSL \\ - Writing-original draft: $J Y$ \\ - Writing-review \& editing: BCJ, SSJ, KSL
}

\section{ORCID}

$\begin{array}{ll}\text { Jiwoong Yu } & 0000-0003-2147-2915 \\ \text { Byong Chang Jeong } & 0000-0002-5399-2184 \\ \text { Seong Soo Jeon } & 0000-0002-3265-6261 \\ \text { Sung Won Lee } & 0000-0001-6608-9050 \\ \text { Kyu-Sung } & 0000-0003-0891-2488\end{array}$

\section{REFERENCES}

1. Mazur DJ, Helfand BT, McVary KT. Influences of neuroregulatory factors on the development of lower urinary tract symptoms/benign prostatic hyperplasia and erectile dysfunction in aging men. Urol Clin North Am 2012;39:77-88.

2. Platz EA, Smit E, Curhan GC, Nyberg LM, Giovannucci E. Prevalence of and racial/ethnic variation in lower urinary tract symptoms and noncancer prostate surgery in U.S. men. Urology 2002; 59:877-83.

3. Kim KS, Jo JK, Lee JA, Choi BY, Moon HS. Do lifestyle factors affect lower urinary tract symptoms? Results from the Korean community health survey. Int Neurourol J 2019;23:125-35.

4. Lee YS, Lee KS, Jung JH, Han DH, Oh SJ, Seo JT, et al. Prevalence of overactive bladder, urinary incontinence, and lower urinary tract symptoms: results of Korean EPIC study. World J Urol 2011; 29:185-90.

5. Puppo P. New technologies for the treatment of benign prostatic hypertrophy: bases for change. J Urol (Paris) 1993;99:360-1.

6. Jeon BJ, Chung H, Bae JH, Jung H, Lee JG, Choi H. Analysis of present status for surgery of benign prostatic hyperplasia in Korea using nationwide healthcare system data. Int Neurourol J 2019;23: 22-9.

7. Kuntzman RS, Malek RS, Barrett DM, Bostwick DG. Potassium-titanyl-phosphate laser vaporization of the prostate: a comparative functional and pathologic study in canines. Urology 1996;48:57583.

8. Homma Y, Kawabe K, Tsukamoto T, Yamaguchi O, Okada K, Aso Y, et al. Estimate criteria for efficacy of treatment in benign prostatic hyperplasia. Int J Urol 1996;3:267-73.

9. Schafer W, Abrams P, Liao L, Mattiasson A, Pesce F, Spangberg A, et al. Good urodynamic practices: uroflowmetry, filling cystometry, and pressure-flow studies. Neurourol Urodyn 2002;21:261-74.

10. Abrams P. Bladder outlet obstruction index, bladder contractility index and bladder voiding efficiency: three simple indices to define bladder voiding function. BJU Int 1999;84:14-5.

11. Gilling P. Holmium laser enucleation of the prostate (HoLEP). BJU Int 2008;101:131-42.

12. Rassweiler J, Teber D, Kuntz R, Hofmann R. Complications of transurethral resection of the prostate (TURP)--incidence, management, and prevention. Eur Urol 2006;50:969-79; discussion 80.

13. McNicholas TA, Singh S. The use of lasers in benign prostatic enlargement. Curr Urol Rep 2000;1:124-31.

14. Tae BS, Jeon BJ, Choi H, Park JY, Bae JH. A novel technique of morcellation using a pneumovesicum after holmium laser enucleation of the prostate in complicated situations: our initial experience and tips. Int Neurourol J 2019;23:46-55.

15. Krambeck AE, Handa SE, Lingeman JE. Holmium laser enucleation of the prostate for prostates larger than 175 grams. J Endourol 2010;24:433-7.

16. Kuntz RM, Ahyai S, Lehrich K, Fayad A. Transurethral holmium laser enucleation of the prostate versus transurethral electrocautery resection of the prostate: a randomized prospective trial in $200 \mathrm{pa}-$ tients. J Urol 2004;172:1012-6.

17. Tan AH, Gilling PJ, Kennett KM, Frampton C, Westenberg AM, Fraundorfer MR. A randomized trial comparing holmium laser enucleation of the prostate with transurethral resection of the prostate for the treatment of bladder outlet obstruction secondary to benign prostatic hyperplasia in large glands (40 to 200 grams). J Urol 2003;170:1270-4.

18. Montorsi F, Naspro R, Salonia A, Suardi N, Briganti A, Zanoni M, et al. Holmium laser enucleation versus transurethral resection of the prostate: results from a 2-center prospective randomized trial 
in patients with obstructive benign prostatic hyperplasia. J Urol 2008;179:S87-90.

19. Bouchier-Hayes DM, Van Appledorn S, Bugeja P, Crowe H, Challacombe B, Costello AJ. A randomized trial of photoselective vaporization of the prostate using the $80-\mathrm{W}$ potassium-titanyl-phosphate laser vs transurethral prostatectomy, with a 1-year follow-up. BJU Int 2010;105:964-9.

20. Han DH, Choo SH, Chung JW, Hong JH, Lee SW. Can 80 W KTP laser vaporization effectively relieve the obstruction in benign prostatic hyperplasia? A nonrandomized trial. World J Mens Health 2012;30:160-5.

21. Guo S, Muller G, Lehmann K, Talimi S, Bonkat G, Puschel H, et al. The 80-W KTP GreenLight laser vaporization of the prostate versus transurethral resection of the prostate (TURP): adjusted analysis of 5-year results of a prospective non-randomized bi-center study. Lasers Med Sci 2015;30:1147-51.

22. Robert G, Cornu JN, Fourmarier M, Saussine C, Descazeaud A, Azzouzi AR, et al. Multicentre prospective evaluation of the learning curve of holmium laser enucleation of the prostate (HoLEP). BJU Int 2016;117:495-9.

23. Seki N, Mochida O, Kinukawa N, Sagiyama K, Naito S. Holmium laser enucleation for prostatic adenoma: analysis of learning curve over the course of 70 consecutive cases. J Urol 2003;170:1847-50.

24. Han DH, Jeong YS, Choo MS, Lee KS. The efficacy of transurethral resection of the prostate in the patients with weak bladder contractility index. Urology 2008;71:657-61.
25. van Venrooij GE, van Melick HH, Eckhardt MD, Boon TA. Correlations of urodynamic changes with changes in symptoms and well-being after transurethral resection of the prostate. J Urol 2002; 168:605-9.

26. van Venrooij GE, van Melick HH, Boon TA. Comparison of outcomes of transurethral prostate resection in urodynamicallyobstructed versus selected urodynamicallyunobstructed or equivocal men. Urology 2003;62:672-6.

27. Tanaka Y, Masumori N, Itoh N, Furuya S, Ogura H, Tsukamoto T. Is the short-term outcome of transurethral resection of the prostate affected by preoperative degree of bladder outlet obstruction, status of detrusor contractility or detrusor overactivity? Int J Urol 2006; 13:1398-404.

28. Seki N, Kai N, Seguchi H, Takei M, Yamaguchi A, Naito S. Predictives regarding outcome after transurethral resection for prostatic adenoma associated with detrusor underactivity. Urology 2006;67: 306-10.

29. Cho MC, Song WH, Park J, Cho SY, Jeong H, Oh SJ, et al. Longterm outcomes of laser prostatectomy for storage symptoms: comparison of serial 5-year followup data between high performance system photoselective vaporization and holmium laser enucleation of the prostate. J Urol 2018;199:1591-9.

30. Jeong J, Lee HS, Cho WJ, Jung W, You HW, Kim TH, et al. Effect of detrusor overactivity on functional outcomes after holmium laser enucleation of the prostate in patients with benign prostatic obstruction. Urology 2015;86:133-8. 